2. To: (Receiving Organization)

-Distribution

5. Proj./Prog./Dept./Div.:

8 Plant Deactivation

8. Originator Remarks:

This EDT is submitted the obtaining approval of the surveillance and maintenance phase safety basis criteria document.

11. Receiver Remarks: 11A. Design 8aseline Document? [X] Yes [] No
3. From: (Originating Organization) B\&W Hanford Co.

6. Design Authority/ Design Agent/Cog. Engr.

R. Hernandez

4. Related EDT No.:

$\mathrm{N} / \mathrm{A}$

7. Purchase Order No.:

$N / A$

9. Equip./Component No.: $\mathrm{N} / \mathrm{A}$

10. System/Bldg./Facility:

B Plant

12. Major Assm. Dwg. No.:

$N / A$

13. Permit/Permit Application No.: $N / A$

14. Required Response Date:

$N / A$

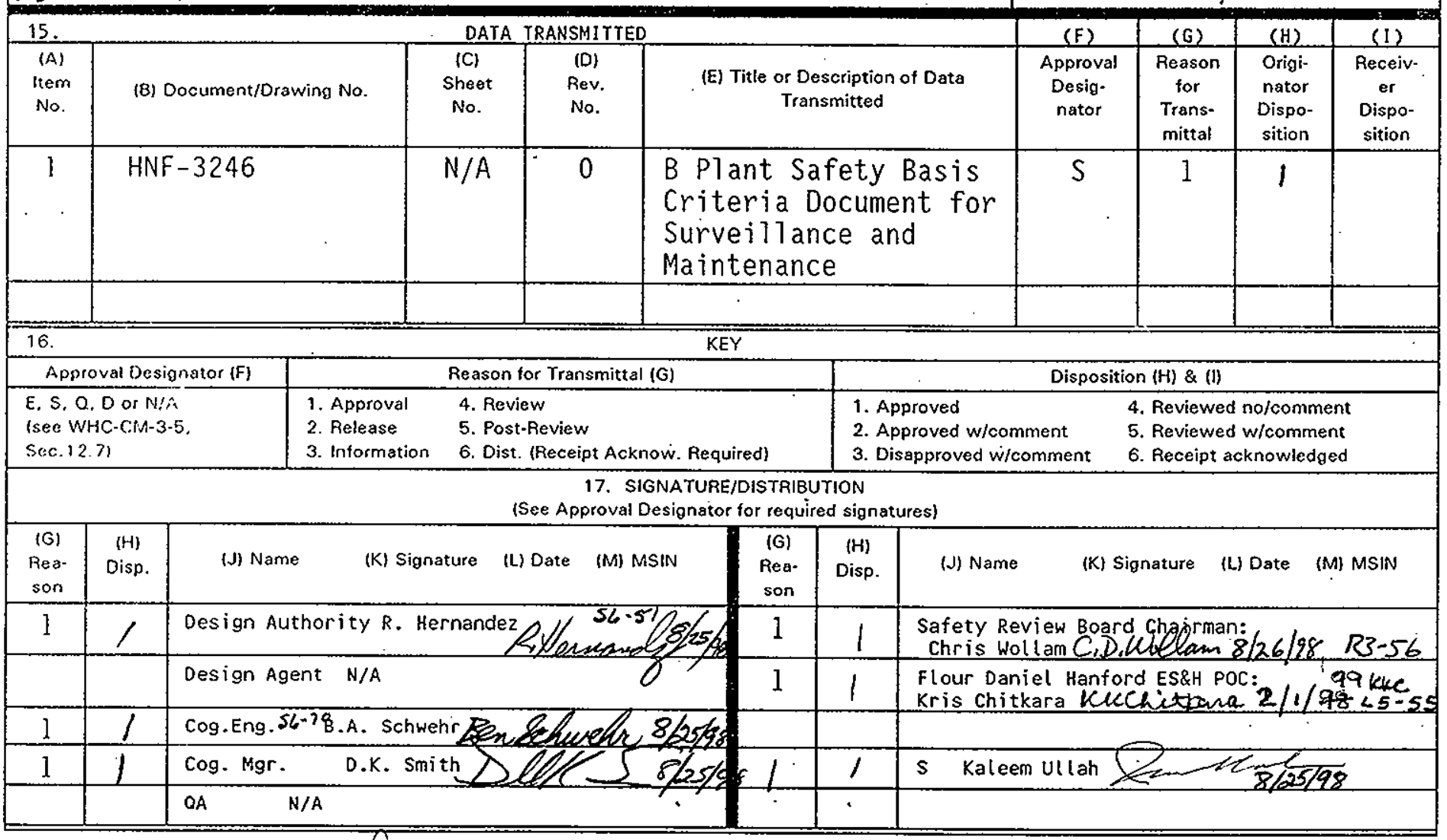

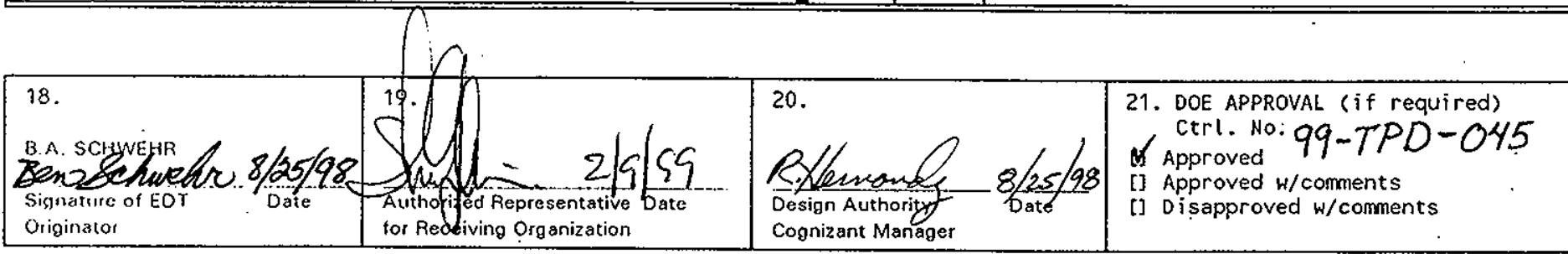

60-7400-172-2(05/96) GEF097 


\section{CRITERIA DOCUMENT FOR B PLANT'S SURVEILLANCE AND MAINTENANCE PHASE SAFETY BASIS DOCUMENT}

B. A. Schwehr

B\&W Hanford Company, Richland, WA 99352

U.S. Department of Energy Contract DE-AC06-96RI13200

EDT : 622571

UC : $\quad 510$

Org Code:

Charge Code: 101242

B\&R Code:

$16 \mathrm{AOO}$

Total Pages: 9

Key Words: B Plant, Safety Basis, Accident Analysis, Safety Equipment, SSC, Safety Significant, Criteria

Abstract: This document is required by the Project Hanford Managing Contractor (PHMC) procedure, HNE-PRO-705, Safety Basis Planning, Documentation, Review, and Approval. This document specifies the criteria that shall be in the $B$ Plant surveillance and maintenance phase safety basis in order to obtain approval of the DOE-RI.

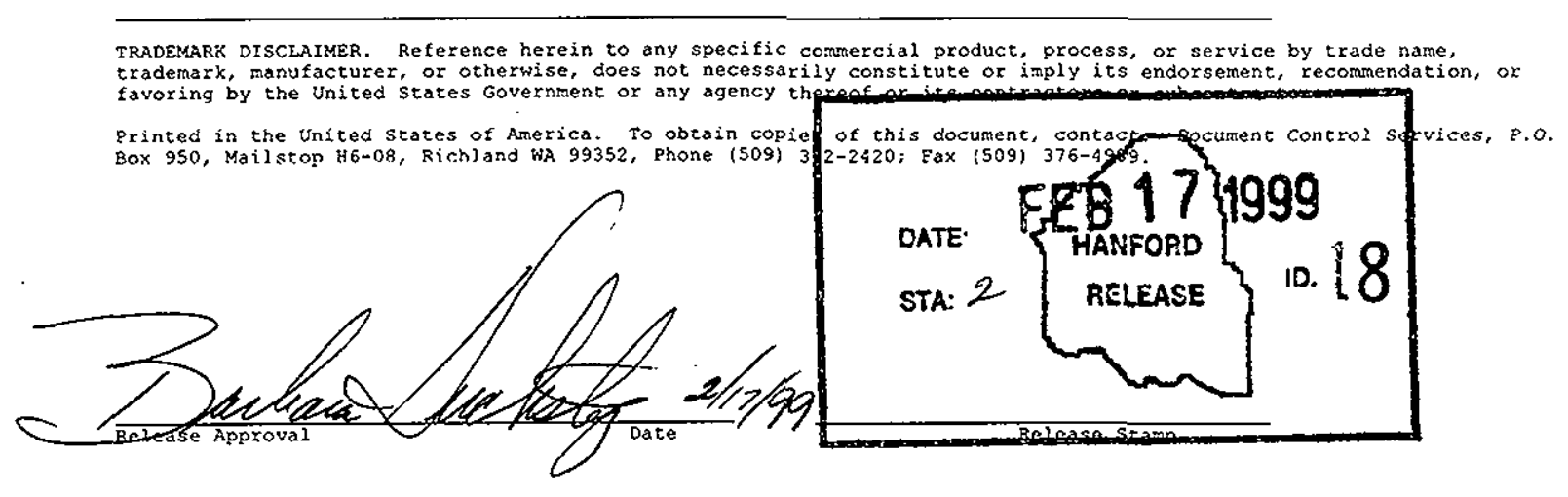

\section{Approved for Public Release}


HNF-3246

REV. 0

\section{Criteria Document}

for B Plant's

Surveillance and Maintenance Phase

Safety Basis Document

\subsection{Introduction}

B\&W Hanford Company (BWHC) has recently completed the deactivation B Plant. B Plant is currently conducting surveillance and maintenance activities in accordance with the current $B$ Plant safety basis, HNF-SD-WM-BIO-003, B Plant Basis for Interim Operations (BIO), Rev. 0, while transitioning the facility into the anticipated long-term Surveillance and Maintenance (S\&M) Phase. A new safety basis is necessary to cover the S\&M Phase configuration, conditions, operations, and hazards, since the current safety basis, the BIO, covers the deactivation mission. This criteria document $(\mathrm{CD})$ has been developed to obtain concurrence from the U.S. Department of Energy, Richland Operations Office (DOE-RL) of the appropriate criteria to address on the S\&M Phase safety basis.

\subsection{Executive Summary}

This CD describes the criteria to be addressed in the S\&M Phase safety basis for the deactivated Waste Fractionization Facility (B Plant) on the Hanford Site in Washington state.

This criteria document describes:

- the document type and format that will be used for the S\&M Phase safety basis, - the requirements documents that will be invoked for the document development, - the deactivated condition of the B Plant facility, - the scope of issues to be addressed in the S\&M Phase safety basis document.

The safety basis for the B Plant S\&M Phase will be a safety analysis report (SAR). The SAR will be developed in accordance with the requirements of the DOE Order 5480.23, Nuclear Safety Analysis Reports, using the guidance of the DOE Standard, DOE-STD-3009-94, Preparation Guide for U.S. Department of Energy Nonreactor Nuclear Facility Safety Analysis Reports.

Development of the safety basis document will be performed in accordance with the Project Hanford Management Contract (PHMC) approved safety analysis process procedures. The Project Hanford procedure, HNF.PRO-430, Rev. 1, Safety Analysis Program, will be followed to develop this safety basis documentation. This criteria document is developed in accordance with the requirements set forth in HNF-PRO-705, Safety Basis Planning, Documentation, Review, and 
Approval.

This safety basis will be developed through a team effort involving BWHC, Bechtel Hanford, Inc. (BHI), and Fluor Daniel Hanford (FDH). The safety basis will address the known and potential facility conditions and hazards associated with the anticipated deactivated facility S\&M activities. Controls will be established, as necessary, to minimize and control the potential hazards in order to protect facility and onsite workers, the public, and the environment. The institutional management and safety programs, that will be implemented by the S\&M operating contractor, will be identified and described in the safety basis document.

\subsection{Purpose for Criteria Document}

The purpose of this criteria document is to establish concurrence between BWHC, FDH, and RL of the criteria that will be used to develop the B Plant S\&M Phase safety basis document. This concurrence is established to enhance timely and effective communications between these partners, provide clear expectations pertaining to deliverables, and gain approval of the safety basis documents with minimal complications and program upsets.

\subsection{Schedule}

BWHC intends to submit the safety basis document to FDH, for submittal to RL by December 31, 1998. The S\&M Phase safety basis will become effective upon DOE-RL approval of the safety basis document(s), completion of facility deactivation, transition of B Plant into the S\&M Phase, and implementation of the S\&M SAR. The safety basis is expected to be implemented by March 31, 1999.

Developing the safety basis on this schedule is considered to fulfill the requirement for providing an annual update of the B Plant safety basis for 1998, in accordance with HNF-PRO-700, Safety Analysis and Technical Safety Requirements; and HNF-PRO-701, Safety Analysis Process Existing Facility. The most recent update to the B Plant safety basis, which was approved on March 6,1998, provides the appropriate safety basis for continued B Plant operations, until this S\&M Phase safety basis is implemented.

\subsection{Document Description}

The S\&M Phase safety analysis report will provide a safety basis document for the S\&M Phase duration.

\subsection{Document Format and Content}

The SAR will serve as a risk management tool which meets the requirements for a safety analysis report as described in DOE Order 5480.23, Nuclear Safety Analysis Reports. 
The SAR format and content will be consistent with the guidelines provided in DOE-STD-3009-94, Preparation Guide for U.S. Department of Energy Nonreactor Nuclear Facility Safety Analysis Reports.

Based on the DOE documents, the safety basis document will reflect a graded approach SAR for a facility having reduced hazards as compared to the previous safety basis; being in a deactivated S\&M Phase; and requiring limited activities within and around the facility.

\subsubsection{Depth and Level of Detail}

The SAR will describe the expected S\&M Phase configuration, operating conditions, hazards, potential accidents and associated consequences, and surveillance and maintenance activities. The level of detail in the SAR will consist of the information necessary to adequately describe the present and potential hazards and the respective controls needed to prevent and/or mitigate accidents and accident consequences. Key elements of the SAR will describe the following:

- Site and facility description

- Facility hazard classification

- Hazards analysis

- Accident selection and analysis

- Identification of controls, such as Technical Safety Requirements, and systems, structures, and components (SSCs) important to safety

- Identification of institutional management and safety programs

- Identification of programmatic commitments.

\subsection{Hazards and Activities To Describe in the S\&M Phase Safety Basis}

\subsubsection{Facility Hazard Category}

B Plant is a Hazard Category 2 nuclear facility, in accordance with the hazard classification analysis contained in the current B Plant BIO, due to the facility radionuclide contamination level in the canyon and the retired filters. This category determination will be evaluated to ensure it is valid following deactivation activities, using DOE-STD-1027-92, Hazard Categorization and Accident Analysis Techniques for Compliance with DOE Order 5480.23, Nuclear Safety Analysis Reports and HNF-PRO-704, Hazard and Accident Analysis Process. Since the radionuclide inventory in the retired filters is not changed by deactivation and that inventory results in a Hazard Category 2 determination, it is expected that the hazard category for $\mathrm{B}$ Plant will not change. 
The initial hazard category determination will recognize existing radiological inventory in the canyon building and the retired filters. The final hazard category determination will be predicated on design basis accidents (DBA)s where credit will be taken for material at risk, compared to total inventory.

\subsubsection{Facility Hazards and S\&M Phase Activities}

The safety basis document will apply to B Plant after it has been deactivated and transitioned into the S\&M Phase. The document will include a hazard analysis, recognizing the potential hazards around and within the deactivated facility. Compared to the earlier missions for B Plant, the remaining hazards are reduced as a result of the removal, stabilization and/or isolation of chemical and radiological materials; limited S\&M activities, operating systems and utilities; and controlled facility access.

In analyzing the hazards that will exist during the S\&M Phase, it is recognized that there is a potential for conditions to change during the undetermined S\&M Phase duration, due to natural phenomena and aging of materials.

Hazards to workers, the public, and the environment will be limited due to the deactivation end states and minimal planned S\&M Phase activities, which are:

- The hazards and facility conditions are known and will be controlled to the maximum extent possible during the S\&M Phase, recognizing inability to control significant natural phenomena.

- Unused utilities, such as water, steam, and electricity will be physically isolated from the facility before the S\&M Phase commences.

- Unused effluent discharges will be physically isolated and blanked from the facility before the S\&M Phase commences.

- During the S\&M Phase, the buildings and yard will be occupied only during routine inspections/surveillances of the conditions and possibly for maintenance/repair activities.

- The deactivated canyon will not store significant quantities of chemicals or radioactive materials.

- The significant radiological inventory in the retired filters is at risk of release from the filter vaults upon occurrence of significant events, such as an explosion and a seismic event, that could damage the containment barriers. Existing design is in place to prevent explosions and 
HNF-3246

REV. 0

mitigate seismic consequences.

- The integrity of the facility structures that contain residual hazardous materials will be monitored and maintained throughout the S\&M Phase.

- Surveillance and maintenance activities of existing SSCs are expected to be performed during the S\&M Phase.

- The S\&M Phase activities will be proceduralized, with predetermined surveillance routes.

During the deactivation phase, the facility structures and roofing materials were assessed for integrity. The structures were found to be sound, but some roofing integrity problems were found. Some repair of roofing materials was performed. During the S\&M Phase, roofs will be monitored and maintenance will be performed as necessary to prevent accelerated degradation of the facilities' structures and to prevent water inleakage and internal contamination migration. It is anticipated that the roofing material on the $221-\mathrm{B}$ canyon structure will be replaced following transition to the S\&M Phase.

\subsection{SAR Document Development Technical Approach}

Development of the safety basis document will be performed in accordance with the Project Hanford Management Contract (PHMC) approved safety analysis process procedures.

The technical approach will begin with a thorough hazards and accident analysis process, recognizing the facility configuration, conditions, and duration anticipated for the S\&M Phase. Particular attention will be focused on the potential for hazards unique to the undetermined S\&M Phase duration, such as facility aging and deterioration.

In evaluating the potential hazards, the facility fire hazards analysis document will be updated to represent the fire hazards of the deactivated facility and the anticipated deactivated duration. The fire hazards analysis for the S\&M Phase will be incorporated into the SAR.

Surveillance and maintenance activities and/or facility preservation controls will be established, commensurate with the magnitude of the associated hazards. Safety controls and technical safety requirements (TSR)s will be established in accordance with the DOE Order 5480.22, Technical Safety Requirements, and HNF-PRO-704, Hazard and Accident Analysis Process. The risk evaluation guidelines in the HNF-PRO-704 procedure will be used to assist in evaluating risk significance and need for controls.

Institutional safety programs will be addressed, as appropriate, to describe safety program integration into the safety basis. Chapters 6-17 of the safety basis document will describe the 
HNF-3246

REV. 0

PHMC commitments to maintain programs to implement the themes outlined by DOE Standard 3009 for these chapters. A crosswalk will be provided in the safety basis document to demonstrate the Hanford ERC program commitments for these functional themes upon facility transition to the ERC contactor.

BWHC may engage outside technical consultants to assist with the identification of hazards, accident analysis, development of surveillance plans and/or general document development.

The safety basis document will be approved in accordance with the requirements in HNF.PRO705, Safety Basis Planning, Documentation, Review, and Approval, and these criteria document commitments.

\subsection{Interfaces}

During the S\&M Phase, B Plant will be affected by a number of interfaces, both physical and programmatic. The safety basis document will consider the impacts of identified physical interfaces, such as the following:

- The B Plant facility is physically adjacent to the Waste Encapsulation and Storage Facility (WESF); however, the shared systems have been isolated/decoupled.

- A remote monitoring and control system may be installed to allow surveillance and control of the B Plant canyon exhaust system from building 271-U at U Plant (200 West area).

- Electrical service, waste disposal, fire protection and site emergency preparedness and other services will be provided by other Hanford site organizations.

\subsection{Supporting Assumptions}

Key assumptions include:

- Recognition of current Hanford site boundaries will be used to distinguish between the onsite and offsite receptors.

- Consideration of a prolonged S\&M Phase duration of decades (up to forty years or greater).

- No demolition of B Plant major structures is anticipated for the duration of the subject safety basis document; some component removal may occur for contamination control, 
HNF-3246

REV. 0

hazardous waste removal, or re-deployment of deactivated equipment.

\subsection{Basis for the SAR Approach}

BWHC committed to provide an updated BIO for the S\&M Phase in the FDH "Safety Analysis Reports and Technical Safety Requirements Implementation Plan" (FDH 1998). As described in the implementation plan (IP), a "graded approach" would be applied to develop the BIO. The graded approach and its defining procedures are identified in the IP. However, applying the graded approach and updating the BIO would require essentially the equal amount of effort that would be required in developing a SAR. Therefore, in a partnering coordination meeting, BWHC, FDH, BHI, and RL agreed to develop a SAR, instead of a BIO.

The development of a SAR for the S\&M Phase will provide an appropriate safety basis for a facility in the deactivated status (S\&M life cycle stage), having reduced hazards and limited operations.

The S\&M Phase safety basis will describe the deactivated facility conditions and activities as compared to the current safety basis, which described the deactivation of the facility. The current BIO demonstrates operable systems being deactivated and low hazards and accident consequences compared with prior operational phases. The S\&M Phase safety basis will demonstrate even lower hazards and accident consequences, due to further reductions in hazardous material inventories during deactivation and reduced operating systems and operations activity levels. Based on the BIO, periodic surveillances will be required during the S\&M Phase, both inside and outside the buildings. These same surveillances will be conducted under the SAR.

Since the existing BIO demonstrates that overall risk levels are already low, the development of the S\&M Phase SAR is not expected to warrant a significant increase in work scope and level of detail beyond that which would be performed to update the BIO.

\subsection{References}

\subsection{DOE Orders and Standards}

DOE Order 5480.22, Technical Safety Requirements

DOE Order 5480.23, Nuclear Safety Analysis Reports

DOE-STD-1027-92, Hazard Categorization and Accident Analysis Techniques for Compliance with DOE Order 5480.23, Nuclear Safety Analysis Reports 
HNF-3246

REV. 0

DOE-STD-3009-94, Preparation Guide for U.S. Department of Energy Nonreactor Nuclear Facility Safety Analysis Reports

\subsection{Hanford Procedures}

HNF-PRO-430, Rev. 1, Safety Analysis Program

HNF-PRO-511 Hazard Classification of Facilities and Segments

HNF-PRO-700, Safety Analysis and Technical Safety Requirements

HNF-PRO-701, Safety Analysis Process - Existing Facility.

HNF-PRO-704, Hazard and Accident Analysis Process

HNF-PRO-705, Safety Basis Planning, Documentation, Review, and Approval

\subsection{Documents}

BIO, 1998, HNF-SD-WM-BIO-003, Rev. 0., B Plant Basis for Interim Operations, B\&W Hanford Co., Richland, Washington.

FDH, 1998, "Safety Analysis Reports and Technical Safety Requirements Implementation Plan", Correspondence No. FDH-9852566, H.J. Hatch, FDH to J.D. Wagoner, RL, dated March 1998. 